\title{
Feasibility of tumor-derived exosome enrichment in the onco-hematology leukemic model of chronic myeloid leukemia
}

\author{
SIMONA BERNARDI ${ }^{1,2^{*}}$, CHIARA FORONI ${ }^{1,2^{*}}$, CAMILLA ZANAGLIO $^{1,2}$, FEDERICA RE $^{1,2}$, \\ NICOLA POLVERELLI $^{1}$, ALESSANDRO TURRA ${ }^{1}$, ENRICO MORELLO ${ }^{1}$, MIRKO FARINA ${ }^{1}$, \\ FEDERICA CATTINA $^{1}$, LISA GANDOLFI ${ }^{1}$, TATIANA ZOLLNER ${ }^{1}$, EUGENIA ACCORSI BUTTINI ${ }^{1}$, \\ MICHELE MALAGOLA $^{1}$ and DOMENICO RUSSO ${ }^{1}$ \\ ${ }^{1}$ Chair of Hematology, Unit of Blood Diseases and Stem Cell Transplantation, \\ Department of Clinical and Experimental Sciences, University of Brescia; ${ }^{2}$ CREA Laboratory \\ (Hematological-Research AIL Centre), ASST Spedali Civili of Brescia, I-25123 Brescia, Italy
}

Received June 3, 2019; Accepted September 12, 2019

DOI: $10.3892 / \mathrm{ijmm} .2019 .4372$

\begin{abstract}
Due to the discovery of their role in intra-cellular communications, exosomes, which carry information specific to the cell of origin, have garnered considerable attention in cancer research. Moreover, there is evidence to suggest the possibility of isolating different exosome sub-populations based on target antigens at the cell surface. Philadelphia chromosome-positive $\left(\mathrm{Ph}^{+}\right)$chronic myeloid leukemia (CML) is a clonal myeloproliferative neoplasia characterized by the breakpoint cluster region-proto-oncogene 1 tyrosine-protein kinase (BCR-ABL1) fusion-gene, derived from the $\mathrm{t}(9 ; 22)$ translocation. Tyrosine kinase inhibitors (TKIs) target BCR-ABL1 protein and induce major or deep molecular responses in the majority of patients. Despite the fact that several studies have demonstrated the persistence of leukemic cells in the bone marrow niche, even following treatment, TKIs prolong patient survival time and facilitate treatment-free remission. These characteristics render CML a plausible model for investigating the feasibility of tumor-derived exosome fraction enrichment. In the present study, patients in the chronic phase (CP) of CML were treated with TKIs, and the quantification of the $B C R-A B L 1$ exosomal transcript was performed using digital PCR (dPCR). The possibility of tumor-derived exosomes enrichment was confirmed, and for the first time, to the best of our knowledge, the detection of the BCR-ABL1 transcript highlighted the presence of active leukemic cells in patients with CP-CML. According to these findings, tumor-derived
\end{abstract}

Correspondence to: Dr Simona Bernardi, CREA Laboratory (Hematological-Research AIL Centre), ASST Spedali Civili of Brescia, Piazzale Spedali Civili 1, I-25123 Brescia, Italy

E-mail: simonabernardi86@gmail.com; simona.bernardi@unibs.it

${ }^{*}$ Contributed equally

Key words: exosomes, digital PCR, chronic myeloid leukemia, minimal residual disease monitoring exosomes may be considered a novel tool for the identification of active leukemic cells, and for the assessment of innovative monitoring focused on the biological functions of exosomes in CML.

\section{Introduction}

Extracellular vesicles (EVs), particularly exosomes, have attracted considerable interest in cancer research owing to the discovery of their role in inter-cellular communications. Exosomes are small endosome-derived lipid nanoparticles $(50-100 \mathrm{~nm})$, actively secreted by exocytosis in the majority of living cells. Exosome release occurs either constitutively or upon induction, under both normal and pathological conditions; this dynamically regulated process is functionally relevant, such that the molecular composition of exosomes reflects the features of the parent cell. Exosomes transport a distinct molecular cargo of proteins and nucleic acids (mRNA, miRNA and genomic DNA) in peripheral blood (PB) and other bio-fluids (e.g., urine and saliva), and are recognized as relevant for the diagnosis and prognosis of certain pathologies, particularly solid tumors. Several studies have demonstrated that the proteins and nucleic acids contained within the exosomes of cancer patients can be isolated and identified as exosomal markers associated with cancer evolution (1-5).

Emerging evidence has also suggested that membrane-bound carriers (EVs and exosomes) released by cancer cells can mediate cell-cell communication via the delivery of their contents (6). When considering leukemic cells, membrane-bound carriers can potentially alter the physiological equilibrium of extra-medullary sites (7), an interesting aspect in hematological malignancies. Innovative approaches, based on the selection of different sub-populations of tumor-associated exosomes (8), appear to be powerful and more informative than conventional isolation methods for diagnostic and prognostic purposes (9-13). This is grounded in the evidence that exosomes released by tumor cells present specific and pan-cancer antigens at the membrane surface (14-16), enabling the possibility to determine the nature of the cell of origin, and to isolate the exosome fraction using the appropriate antibodies. Exosome enrichment has 
already been explored in the solid tumors field, with successful results (17-20).

Currently, at least to the best of our knowledge, there are no studies available reporting the possibility of enriching the tumor-derived exosome fraction in patients affected by different types of leukemia. However, certain groups have revealed that exosomes isolated from cell line cultures modulate the crosstalk between leukemia cells and the bone marrow (BM) microenvironment, and that they also carry molecular tumor markers (21-24). Moreover, recent studies have indicated that leukemia-derived exosomes can be utilized as prognostic (25), diagnostic (26) and therapeutic biomarkers (27) for individuals suffering from different hematologic malignancies, such as acute myeloid leukemia (28-30), multiple myeloma (31) and chronic lymphocytic leukemia (32).

Corrado et al (33) reported that chronic myeloid leukemia (CML) cells may release exosomes, and that the addition of these vesicles to vascular endothelial cells, as well as to BM stromal cells cultures, affects both in vitro and in vivo tumor progression. CML is a clonal myeloproliferative disease characterized by a reciprocal translocation between chromosomes 9 and 22 [t(9;22)], resulting in Philadelphia chromosome-positive $\left(\mathrm{Ph}^{+}\right) \mathrm{CML}$ and the formation of a new fusion genes encoding for the chimeric breakpoint cluster region-proto-oncogene 1 tyrosine-protein kinase (BCR-ABL1) p210 oncoprotein (34). BCR-ABL1 exhibits a constitutively high tyrosine kinase activity and is considered the

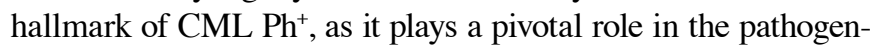
esis (35) and progression of the disease.

CML is characterized by three distinct disease phases: The chronic phase $(\mathrm{CP})$, the accelerated phase and the blastic phase. Indeed, BCR-ABL1 reduction or ablation is necessary to avoid progression to the advanced blastic phase of disease (36). Currently, treatment with tyrosine kinase inhibitors (TKIs) targeting the BCR-ABL1 p210 protein is the only treatment able to successfully attenuate the progression of CML to the blastic phase, inducing a significant reduction in the expression of the $B C R-A B L 1$ transcript, namely the major or deep molecular response (DMR), in $80-90 \%$ of patients. The detection and quantification of the $B C R-A B L 1$ transcript in $\mathrm{PB}$ cells by reverse transcription-quantitative PCR (RT-qPCR), normalized to a housekeeping gene, is recognized as the international standardized method for determining minimal residual disease (MRD), and plays a key role in the management of patients with CML $(37,38)$. As aforementioned, the MRD level is distinguished as a major molecular response (MMR), with BCR-ABL1 $\leq 0.1 \%$ and ABL1 > 10.000 copies; or a DMR if BCR-ABL1 $\leq 0.01 \%$, or ABL $>10.000$ copies when BCR-ABL1 is undetectable (37). The achievement of the DMR is associated with survival and the opportunity for treatment-free remission (TFR).

Nevertheless, numerous studies have demonstrated the persistence of CML leukemic cells in the BM niche following treatment, even in patients with undetectable levels of the $B C R-A B L 1$ transcript by RT-qPCR. The persistence of these cells in patients with CML has also been confirmed in clinical practice, where molecular relapse is experienced in $\sim 50 \%$ of patients undergoing TKI discontinuation programs (39-42). Residual leukemic cells may be quiescent stem cells, detectable only by CD26 recognition methods (43), or active CML cells. Residual BM CML cells, which indicate the activation of the
BCR-ABL1 pathways, may re-enter the proliferative cycle and may be responsible for molecular relapse. In this scenario, the persistence of the residual active leukemic cells pool, surviving indefinitely into tumor-specific niches of the BM, is not evaluated by the standardized MRD monitoring system. Therefore, a deep and undetectable MR measured on PB cells may not be sufficient to detect the persistence of BM-active CML leukemic cells.

Collectively, these biological findings render $\mathrm{Ph}^{+} \mathrm{CML}$ a suitable model with which to explore the feasibility of tumor-exosome enrichment in hematological malignancies, and consequently, to investigate new possibilities for the detection and evaluation of residual tumor-cell activity. At present, limited data concerning exosome evaluation in patients with CML, and the identification of the $B C R-A B L 1$ transcript in these vesicles have been reported. To the best of our knowledge, only Kang et al (44) demonstrated the possibility of quantifying the $B C R-A B L 1$ transcript in the total exosome pool, conventionally isolated from the $\mathrm{PB}$ of patients with CML in the advanced disease phases. Conversely, negative results were obtained when detecting the transcript by nested PCR in TKI-treated patients with CML in the CP.

Supported by the above-mentioned considerations, CML was identified as the most suitable hematological neoplasia for a feasibility study on neoplastic exosome enrichment. The present study indicates the results of an explorative feasibility study based on the quantification of the $B C R-A B L 1$ transcript by digital PCR (dPCR), a more specific and accurate tool for the detection of the MRD in patients with CML $(45,46)$, on a tumor-derived exosome fraction enriched in the $\mathrm{PB}$ of patients in the $\mathrm{CP}$, who are also receiving TKI treatment.

\section{Materials and methods}

Patients and controls. A total of 10 patients with $\mathrm{Ph}^{+} \mathrm{CML}$ in the CP, treated with TKIs [imatinib (IM) or dasatinib (DAS)] and in DMR as confirmed by conventional RT-qPCR; 10 healthy subjects; and 4 patients affected by $\mathrm{Ph}$ negative $\left(\mathrm{Ph}^{-}\right)$hematological malignancies, were enrolled in the present study. For CML case no. 1, 5 additional samples from diagnosis to the DMR achievement were retrospectively analyzed. Healthy subjects and $\mathrm{Ph}^{-}$patients served as healthy and pathological $\mathrm{Ph}^{-}$controls, respectively. The 10 healthy subjects were selected based on having no previous onco-hematological diseases, no relatives affected by hematological or solid tumors, not undergoing therapeutic treatment, and having no comorbidities at the time of sampling. They were 3 males and 7 females, with a median age of 31.5 years (range, 27-49 years). The pathological $\mathrm{Ph}^{-}$control group included 1 case of acute myeloid leukemia, 1 case of multiple myeloma, 1 case of myelofibrosis and 1 of acute lymphoblastic leukemia B. The absence of chromosomal rearrangement involving BCR or ABL genes was evaluated by FISH and confirmed by RT-qPCR. The characteristics of the patients and the control cohorts are presented in Tables I and II, respectively.

The present explorative study was approved by the Ethics Committee of Brescia (local study no. NP2370 approved in May, 2016) and performed according to good clinical practice and Declaration of Helsinki. All patients and subjects gave their written informed consent for the enrollment in the study, the use of their samples for research purposes and for the publication of the encompassed data. 
Table I. The clinical characteristics of the CML patient cohort.

\begin{tabular}{lc}
\hline Variables & Median (range) \\
\hline No. of $\mathrm{Ph}^{+} \mathrm{CML}$ patients & 10 \\
Sex $(\mathrm{M} / \mathrm{F})$ & $6 / 4$ \\
Age at study (median and range in years) & $70(33-85)$ \\
BCR-ABL transcript at diagnosis & \\
$\mathrm{B} 3 \mathrm{~A} 2$ & 7 \\
$\mathrm{~B} 2 \mathrm{~A} 2$ & 3 \\
$\mathrm{TKI}$ current treatment & \\
$\mathrm{IM}$ & 7 \\
$\mathrm{DAS}$ & 3 \\
$\mathrm{DMR}$ duration (months) & \\
$\mathrm{MR}^{\text {at study }}$ & $(33-81)$ \\
$\mathrm{MR}^{4.0}$ total/undetectable & $1 / 0$ \\
$\mathrm{MR}^{4.5}$ total/undetectable & $3 / 1$ \\
$\mathrm{MR}^{5.0}$ total/undetectable & $6 / 5$ \\
\hline
\end{tabular}

CML, chronic myeloid leukemia; BCR-ABL1, breakpoint cluster region-proto-oncogene 1 tyrosine-protein kinase; IM, imatinib; DAS, dasatinib; MR, molecular response.

Plasma collection, exosome isolation and RNA extraction. To isolate exosomes, $4.9 \mathrm{ml}$ of EDTA-treated $\mathrm{PB}$ from patients and healthy donors was centrifuged at 2,000 $\mathrm{x} g$ for $10 \mathrm{~min}$ in EDTA-K2 gel S-monovette ${ }^{\circledR}$ tubes (Sarsted Inc.). To avoid cellular contamination, the plasma was aspirated up to $1 \mathrm{~cm}$ of the gel front, and stored at $-80^{\circ} \mathrm{C}$ until analysis. Upon thawing, $2 \mathrm{ml}$ of plasma from each sample was clarified by centrifugation $\left(1,200 \mathrm{x} \mathrm{g}\right.$ for $\left.20 \mathrm{~min}, 10^{\circ} \mathrm{C}\right)$ to eliminate residual red blood cells and cellular debris.

Following tumor exosome isolation from the plasma, exosomal RNA purification was performed using the SoRTEV ${ }^{\mathrm{TM}}$ EV-RNA Low Volume Enrichment kit (Exosomics S.p.A), according to the manufacturer's protocol, and the total exosomal RNA was eluted in a volume of $15 \mu \mathrm{l}$. A total of $12 \mu 1$ extracted RNA was reverse-transcribed using the RNAUsScript Reverse Transcriptase kit (LeGene Biosciences) following the manufacturer's instructions. The final reaction volume was $20 \mu \mathrm{l}$, and $5 \mu \mathrm{l}$ was used for each dPCR quantification. The isolation of the total exosome fraction from the plasma of 5 healthy controls (cases healthy controls nos. 6, 7, 8,9 and 10) and of 10 CML samples (case nos. 5, 6, 7, 8, 9 and 1a-e) was performed using the Total Exosome Isolation kit and Total Exosome RNA and Protein Isolation kit (Thermo Fisher Scientific, Inc.) according to the manufacturer's instructions.

\section{$R T-q P C R$ and $d P C R$ analyses}

$R T-q P C R$ analysis. Conventional RT-qPCR was carried out at the Reference Laboratory (Spedali Civili of Brescia, member of LabNet, Italy), according to European Leukemia Net (ELN) Guidelines (37). A total of $10 \mathrm{ml}$ of PB was obtained and used for RT-qPCR analysis for all subjects enrolled in the present study.

Molecular responses (MRs) by RT-qPCR were defined according to the latest laboratory recommendations and using
$A B L 1$ as a reference gene. Measurable MRs were assigned following the international scale (IS), and scored $\mathrm{MR}^{4.0}$ if $B C R-A B L 1 \%$ IS was $\leq 0.01 \%, \mathrm{MR}^{4.5}$ if $B C R-A B L 1 \%$ IS was $\leq 0.0032 \%$, and $\mathrm{MR}^{5.0}$ if $B C R-A B L 1 \%$ IS was $\leq 0.001$. The minimum sum of the $A B L 1$ reference gene transcripts, irrespective of $B C R-A B L 1$ detection, was 10,000, 32,000 and 100,000 for $\mathrm{MR}^{4.0}, \mathrm{MR}^{4.5}$ and $\mathrm{MR}^{5.0}$, respectively (37). The quantification values of BCR-ABL1 and ABL1 performed by the Reference Laboratory are presented in Table III.

dPCR analysis. Since dPCR has been demonstrated to be more accurate and sensitive than conventional RT-qPCR for the quantification of the MRD in patients with CML (by detecting the $B C R-A B L 1$ transcript), in order to compare the results obtained from the tumor exosomes, $B C R-A B L 1 \mathrm{dPCR}$ analysis was first performed on cDNA from PB cells, as previously described $(45,46)$. To reduce bias, the cDNA samples were the same as those used during the RT-qPCR analysis.

A $16 \mu \mathrm{l}$ reaction mixture was prepared, containing $8 \mu \mathrm{l}$ 2X QuantStudio 3D Digital PCR Master Mix (Thermo Fisher Scientific, Inc.), 0.8 $\mu 1$ 20X TaqMan-MGB-FAM-probe assay for $B C R-A B L 1,1.1 \mu \mathrm{l} \mathrm{cDNA}(50 \mathrm{ng} / \mu \mathrm{l})$ and $6.1 \mu 1$ nuclease-free water (Qiagen, Inc.). The negative control reaction mix contained $8 \mu 1$ 2X QuantStudio 3D Digital PCR Master Mix, $0.8 \mu 1$ 20X TaqMan-MGB-FAM-probe assay for $B C R-A B L 1$ and $7.2 \mu 1$ nuclease-free water; one negative control was loaded for each round of thermal cycling, containing samples prepared with the same mix. The reverse transcription negative control reaction mixture contained $8 \mu \mathrm{l} 2 \mathrm{X}$ QuantStudio 3D Digital PCR Master Mix, $0.8 \mu 1$ 20X TaqMan-MGB-FAM-probe assay for $B C R-A B L 1,1.2 \mu 1$ reverse transcription blank and $6.1 \mu 1$ nuclease-free water. dPCR analysis was performed on cDNA extracted from exosomes, and was set up and optimized considering the low quantity of RNA within vesicles.

To quantify the RNA extracted from the vesicles, the $Y 4$ transcript was used as an internal reference gene $(47,48)$, and quantified using a 20X TaqMan-MGB-FAM-probe assay for Y4 (5' Y4 RNA) (49). The conventional ABL1 gene was excluded since it is not considered a reliable internal reference gene for exosomes $(47,48,50-52)$.

A $16 \mu \mathrm{l}$ of reaction mixture containing $8 \mu 12 \mathrm{X}$ QuantStudio 3D Digital PCR Master Mix (Thermo Fisher Scientific, Inc.), $0.8 \mu 1$ 20X TaqMan-MGB-FAM-probe assay for $B C R-A B L 1$, $5 \mu \mathrm{l}$ diluted cDNA and $2.2 \mu \mathrm{l}$ nuclease-free water (Qiagen, Inc.). The negative control reaction contained no cDNA and was made up to a total of $16 \mu \mathrm{l}$ with $7.2 \mu \mathrm{l}$ nuclease-free water; a negative control sample was used for each round of thermocycling (as aforementioned). The reverse transcription negative control contained $8 \mu \mathrm{l}$ 2X QuantStudio 3D Digital PCR Master Mix, $0.8 \mu 1$ 20X TaqMan-MGB-FAM-probe assay for $B C R-A B L 1$, $5 \mu \mathrm{l}$ reverse transcription blank and $2.2 \mu \mathrm{l}$ nuclease-free water. The same analysis parameters were replicated using the $20 \mathrm{X}$ TaqMan-MGB-FAM-probe assay for $Y 4$.

For each sample of the cellular and exosomal cDNA groups, $15 \mu \mathrm{l}$ of each reaction mixtures was loaded onto a QuantStudio 3D Digital PCR 20K Chip (Thermo Fisher Scientific, Inc.) using the automatic chip loader, and the signal was amplified using the following thermocycling profile: $95^{\circ} \mathrm{C}$ for $8 \mathrm{~min}, 45$ cycles at $95^{\circ} \mathrm{C}$ for $15 \mathrm{sec}$ and $60^{\circ} \mathrm{C}$ for $1 \mathrm{~min}$, with a final extension step at $60^{\circ} \mathrm{C}$ for $2 \mathrm{~min}$. Amplification 
Table II. Clinical characteristics of Philadelphia-negative patients included in the study.

\begin{tabular}{|c|c|c|c|c|}
\hline & $\mathrm{Ph}^{-1} 1$ & $\mathrm{Ph}^{-} 2$ & $\mathrm{Ph}^{-} 3$ & $\mathrm{Ph}^{-} 4$ \\
\hline Sex & M & $\mathrm{F}$ & $\mathrm{F}$ & M \\
\hline Diagnosis & $\begin{array}{c}\text { Acute lymphoblastic } \\
\text { leukemia B }\end{array}$ & Acute myeloid leukemia & Myelofibrosis & Multiple myeloma \\
\hline Age (years) & 38 & 67 & 64 & 49 \\
\hline Disease phase & Diagnosis & $\begin{array}{c}\text { CR after consolidation } \\
\text { therapy }\end{array}$ & $\mathrm{CR}$ at 3 months post allo-HSCT & Relapse \\
\hline
\end{tabular}

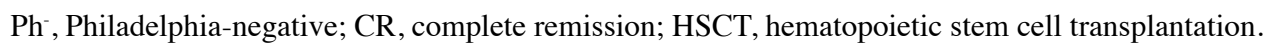

Table III. Results of the quantification of $B C R-A B L 1 / A B L 1$ by RT-qPCR aligned with IS and of $B C R$ - $A B L 1$ and $A B L 1$ transcript by RT-qPCR in CML patients, before the normalization and the calculation of the ratio.

\begin{tabular}{|c|c|c|c|c|}
\hline \multirow[b]{2}{*}{ Case no. } & \multicolumn{2}{|c|}{$\begin{array}{c}\text { RT-qPCR } \\
B C R-A B L 1 / A B L 1\end{array}$} & \multirow[b]{2}{*}{$B C R-A B L 1$ transcript copies } & \multirow[b]{2}{*}{$A B L 1$ transcript copies } \\
\hline & MR & IS & & \\
\hline 1 & 4.5 & 0.0013 & 3 & 94,484 \\
\hline 2 & 4.5 & 0 & 0 & 34,853 \\
\hline 3 & 4.5 & 0.0031 & 4 & 96,732 \\
\hline 4 & 5.0 & 0 & 0 & 102,813 \\
\hline 5 & 5.0 & 0 & 0 & 109,406 \\
\hline 6 & 5.0 & 0 & 0 & 101,818 \\
\hline 7 & 5.0 & 0 & 0 & 110,005 \\
\hline 8 & 5.0 & 0 & 0 & 105,513 \\
\hline 9 & 5.0 & 0.0008 & 3 & 143,946 \\
\hline 10 & 4.0 & 0.0053 & 8 & 148,729 \\
\hline 1a & 0.0 & 19.528 & 4,480 & 23,198 \\
\hline $1 b$ & 2.0 & 0.1021 & 142 & 136,406 \\
\hline 1c & 3.0 & 0.0112 & 5 & 48,072 \\
\hline $1 d$ & 3.0 & 0.0707 & 70 & 105,953 \\
\hline 1e & 4.0 & 0.0054 & 8 & 148,921 \\
\hline
\end{tabular}

CML, chronic myeloid leukemia; $B C R-A B L 1$, breakpoint cluster region-proto-oncogene 1 tyrosine-protein kinase; MR, molecular response; IS, international scale.

was followed by chip imaging, and secondary analysis was performed using the QuantStudio 3D Analysis Suite Cloud Software (version 3.1.5). All samples were independently analyzed by two different operators, and quantification was performed in a blinded manner; in the case of a discrepancy, a third IPCR analysis was performed. The final results were expressed as the means of the number of $B C R-A B L 1$ and $Y 4$ copies/ $\mu$ l of reaction, and the emission threshold was fixed at 4,000 relative fluorescence units.

The final results for the exosomes samples were reported as ratio of $B C R-A B L 1 / Y 4$ transcript, and normalized to the total amount of plasma used for tumor exosome isolation and enrichment. The quantification results are presented in Table IV. Y4 was also quantified using dPCR on the total exosome fraction of the healthy controls (case nos. 6, 7, 8,9 and 10) and in CML samples (nos. 5, 6, 7, 8, 9 and 1a-e), isolated using the Total Exosome Isolation kit and Total Exosome RNA and Protein Isolation kit (Thermo Fisher Scientific, Inc.).

\section{Results}

The present study aimed to evaluate the feasibility of enriching the tumor-exosome fraction in patients with $\mathrm{Ph}^{+} \mathrm{CML}$ in the $\mathrm{CP}$ and undergoing treatment with TKIs by detecting the $B C R-A B L 1$ transcript.

The SoRTEV ${ }^{\text {тм }}$ EV-RNA Low Volume Enrichment kit (EXOSOMICS Spa, Siena, Italy) is an innovative tool to selectively isolate tumor-enriched exosomes from biological fluids. Exosomal purification is achieved using immuno-affinity beads coated with proprietary antibodies against exosome 
Table IV. Results of the quantification of $B C R-A B L 1 / A B L 1$ by RT-qPCR aligned with IS and of $B C R-A B L 1$ transcript by dPCR in CML patients.

\begin{tabular}{|c|c|c|c|c|c|c|c|c|c|c|}
\hline \multirow[b]{2}{*}{ Case no. } & \multicolumn{2}{|c|}{$\begin{array}{c}\text { RT-qPCR } \\
B C R-A B L 1 / \\
A B L 1\end{array}$} & \multicolumn{2}{|c|}{$\begin{array}{c}\text { dPCR PB } \\
\text { cells } B C R-A B L 1\end{array}$} & \multicolumn{3}{|c|}{ dPCR EXO $B C R-A B L 1$} & \multicolumn{3}{|c|}{ dPCR EXO Y4 } \\
\hline & MR & IS & DOTS & $\begin{array}{l}\text { Copies } / \mu 1 \\
\text { of reaction }\end{array}$ & DOTS & $\begin{array}{l}\text { Copies } / \mu 1 \\
\text { of reaction }\end{array}$ & $\begin{array}{l}\text { Copies/ml } \\
\text { plasma }\end{array}$ & DOTS & $\begin{array}{l}\text { Copies } / \mu 1 \\
\text { of reaction }\end{array}$ & $\begin{array}{c}\text { Copies/ml } \\
\text { plasma }\end{array}$ \\
\hline 1 & 4.5 & 0.0013 & 2 & 0.161 & 3 & 0.256 & 6.67 & 294 & 28.239 & $1,058.9$ \\
\hline 2 & 4.5 & 0 & 1 & 0.0857 & 1 & 0.091 & 4.74 & 100 & 10.579 & 661.18 \\
\hline 3 & 4.5 & 0.0031 & 3 & 0.226 & 2 & 0.158 & 8.23 & 251 & 22.711 & $1,419.44$ \\
\hline 4 & 5.0 & 0 & 5 & 0.439 & 4 & 0.324 & 20.25 & 2 & 0.299 & 37.37 \\
\hline 5 & 5.0 & 0 & 0 & 0 & 2 & 0.226 & 14.12 & 11 & 0.848 & 35.3 \\
\hline 6 & 5.0 & 0 & 2 & 0.188 & 3 & 0.219 & 13.69 & 6 & 0.432 & 54.0 \\
\hline 7 & 5.0 & 0 & 1 & 0.0773 & 1 & 0.072 & 4.5 & 30 & 2.39 & 298.75 \\
\hline 8 & 5.0 & 0 & 1 & 0.0781 & 5 & 0.407 & 12.72 & 11 & 0.915 & 57.19 \\
\hline 9 & 5.0 & 0.0008 & 1 & 0.0853 & 4 & 0.329 & 10.28 & 8 & 0.613 & 38.31 \\
\hline 10 & 4.0 & 0.0053 & 5 & 0.441 & 5 & 0.378 & 14.76 & 76 & 5.945 & 928.9 \\
\hline $1 \mathrm{a}$ & 0.0 & 19.528 & 49 & 3.014 & 8 & 0.645 & 80.625 & 97 & 9.146 & $1,143.25$ \\
\hline $1 b$ & 2.0 & 0.1021 & 11 & 0.905 & 5 & 0.381 & 47.625 & 58 & 4.973 & 621.625 \\
\hline $1 \mathrm{c}$ & 3.0 & 0.0112 & 3 & 0.250 & 5 & 0.377 & 47.125 & 18 & 1.288 & 161 \\
\hline $1 d$ & 3.0 & 0.0707 & 3 & 0.234 & 3 & 0.241 & 15.0625 & 24 & 1.734 & 108.375 \\
\hline $1 \mathrm{e}$ & 4.0 & 0.0054 & 1 & 0.0725 & 3 & 0.228 & 14.25 & 11 & 0.909 & 56.813 \\
\hline
\end{tabular}

Quantification was performed on PB cells and tumor exosome fraction. In the column entitled 'dPCR EXO Y4' the results of the quantification of $Y 4$ performed by dPCR on the tumor exosome fraction are reported. Case nos. 1a, 1b, 1c and 1d and 1e refer to CML case no. 1 monitored at different disease phases. CML, chronic myeloid leukemia; BCR-ABL1, breakpoint cluster region-proto-oncogene 1 tyrosine-protein kinase; MR, molecular response; IS, international scale.

pan-tumor surface antigens, and allows the selective isolation of tumor-derived nucleic acids from tumor-enriched exosomes.

Following exosome enrichment, $B C R-A B L 1$ was quantified in PB cells by RT-qPCR, following the MRD monitoring gold standards. The $B C R-A B L 1$ transcript was also quantified by $\mathrm{dPCR}$ on PB cell extracts and cDNA was extracted from tumor-derived exosomes, since it has been described as a more accurate and sensitive approach for the detection of deeper and more stable molecular responses (45). dPCR has been considered the most effective tool for the quantification of the target transcript in exosome cDNA, due to the low amount of nucleic acid in these vesicles. The results obtained from tumor-derived exosomes were subsequently compared with those obtained by dPCR from PB cells.

RT-qPCR BCR-ABL1 quantification. RT-qPCR was performed on the control samples following the international ELN Guidelines; the $B C R-A B L 1$ transcript was not detected; thus, these subjects were confirmed as controls.

The quantification of the $B C R-A B L 1$ transcript in the CML patient samples was also performed following the international ELN Guidelines and the MR classes were assigned according to the IS (37). The replicates were 3 for BCR-ABL1 quantification and 2 for ABL1 quantification, for all samples. At enrollment, 1/10 (10\%) CML patients resulted in $\mathrm{MR}^{4.0}, 3 / 10$ (20\%) resulted in $\mathrm{MR}^{4.5}$ and 6/10 (70\%) resulted in $\mathrm{MR}^{5.0} ; 1 / 3$ (33\%) of patients with $\mathrm{MR}^{4.5}$ and $5 / 6(83 \%)$ of patients in $\mathrm{MR}^{5.0}$ presented with undetectable levels of $B C R-A B L 1$ transcript, respectively (Tables I and III).

dPCR BCR-ABL1 quantification in PB cells. The cDNA obtained from PB cells of both the patients with CML and the controls was deemed suitable for the quantification of $B C R-A B L 1$ by dPCR. No $B C R-A B L 1$ transcript was detected in the healthy controls or in the $\mathrm{Ph}^{-}$pathological controls, while the fusion gene transcript was quantifiable in all but one of the CML patient samples; this sample (case no. 5) also possessed an $\mathrm{MR}^{5.0}$ (undetectable by RT-qPCR) following the IS. The median quantification value of the fusion-gene transcript in the CML patient samples was $0.123 B C R-A B L 1$ copies/ $\mu$ l (range $0-0.441$ ), and the raw dPCR data are presented in Table IV.

dPCR BCR-ABL1/Y4 quantification in the tumor-exosome enriched fraction. The $B C R-A B L 1$ expression levels were quantified by dPCR from cDNA isolated from the exosomes of the patients with CML and the control subjects. In order to estimate the total amount of the exosomal RNA, Y4 was quantified. The raw quantification data, expressed as both copies $/ \mathrm{ml}$ of reaction and copies/ml of plasma, are presented in Table IV.

In the healthy control subjects, dPCR analysis revealed an auto-fluorescence smeared signal at the 6-carboxyfluorescein (FAM) wavelength, for both in $Y 4$ (Fig. 1A) and $B C R-A B L 1$ (Fig. 1B). The signal was not superimposable 
A

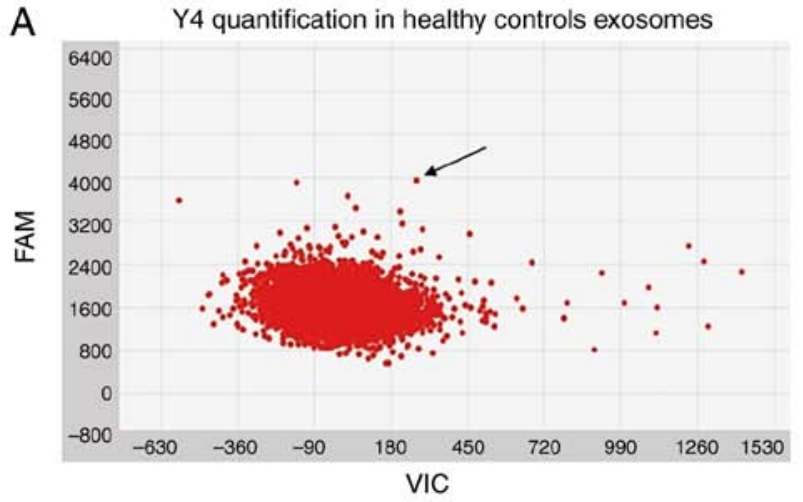

C

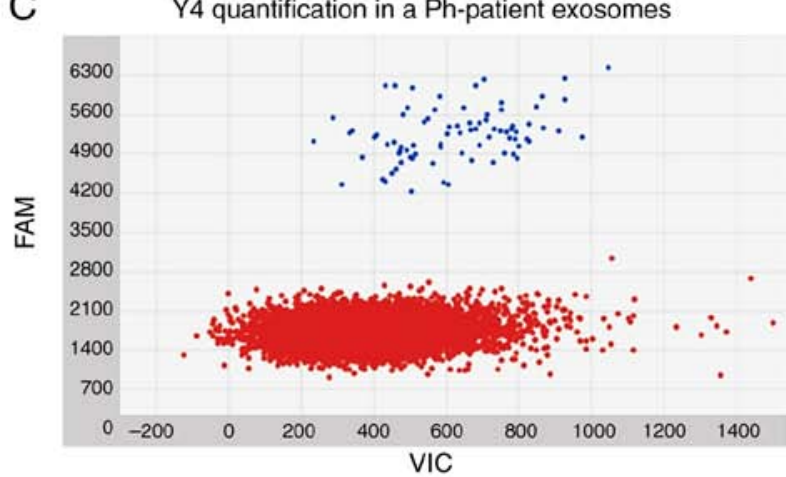

B BCR-ABL1 quantification in healthy controls exosomes

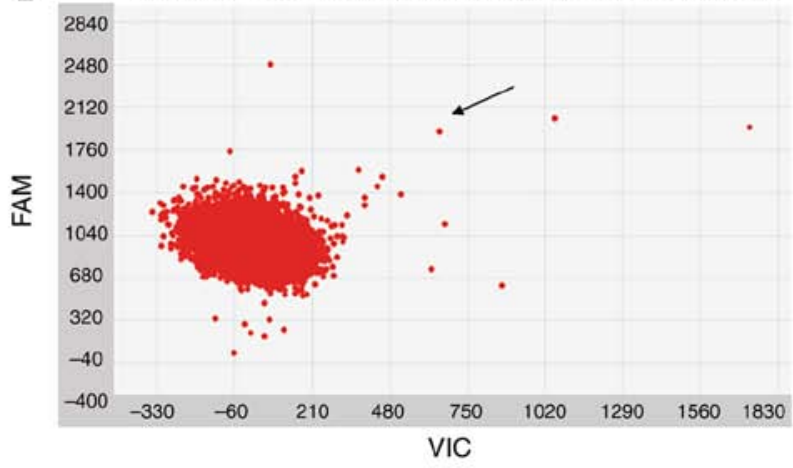

D

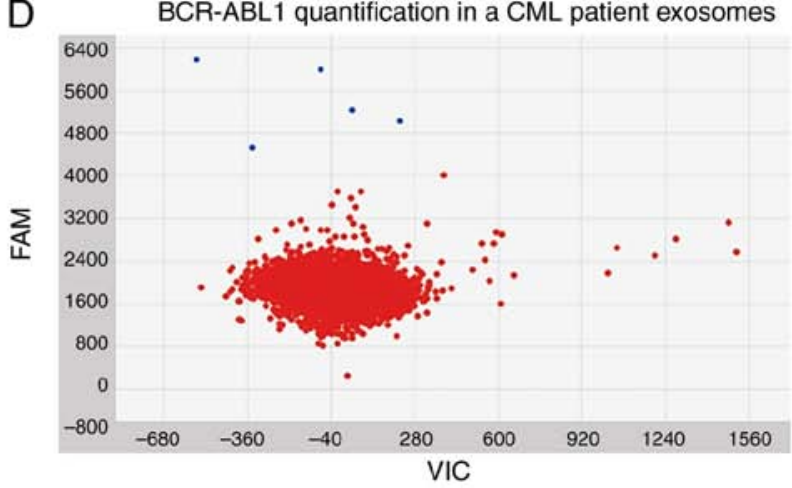

Figure 1. Images obtained during the analysis of dPCR chips by Analysis Suite software. In all the figures, the X-axis corresponds to the VIC wavelength channel. Although no VIC-labeled probe was present in the preparation and no signal resulted emitted in VIC wavelength channel, a baseline signal is naturally present in all the samples and correspond to the background of emission. VIC and FAM are the two wavelengths automatically analyzed by Analysis Suite software and are reported in all the graphs generated by this software. (A) The loaded sample was tumor-enriched exosome cDNA from healthy control number 2. Red dots represent the negative micro-reactions. The y-axis corresponds to FAM (BCR-ABL1 probe label) wavelength emission intensity. In the image, a smear of negative micro-reactions in FAM channel is appreciable (arrow). (B) The loaded sample was tumor-enriched exosome cDNA from healthy control number 2 . Red dots represent the negative micro-reactions. Y-axis corresponds to FAM (Y4 probe label) wavelength emission intensity. In the image, a smear of negative micro-reactions in FAM channel is appreciable (arrow). (C) The loaded sample was tumor-enriched exosome cDNA from $\mathrm{Ph}^{-}$control number 4. Red and blue dots represent the negative and the Y4 positive micro-reactions, respectively. Y-axis corresponds to FAM (Y4 probe label) wavelength emission intensity. (D) The loaded sample was tumor-enriched exosome cDNA from CML patient number 10. Red and blue dots represent the negative and the BCR-ABL1 positive micro-reactions, respectively. The y-axis corresponds to FAM (BCR-ABL1 probe label) wavelength emission intensity. dPCR, digital PCR; BCR-ABL1, breakpoint cluster region-proto-oncogene 1 tyrosine-protein kinase; CML, chronic myeloid leukemia; Ph-, Philadelphia chromosome-negative.

with FAM-labeled probe signal, and there was no separation in terms of fluorescence intensity between the negative and auto-fluorescent microparticles. Nevertheless, the identified signal was under the emission threshold of all samples, and was therefore assumed to be background noise.

$B C R-A B L 1$ was not amplified by dPCR in the $\mathrm{Ph}^{-}$controls, with the exception of the multiple myeloma patient sample, where 2 copies were identified. On the contrary, a positive FAM signal was detectable in all the samples tested for the internal reference gene. The median quantification for the $Y 4$ transcript was 58.93 (range, 14.31-365.31), which was normalized for plasma volume. The $\mathrm{Ph}^{-} 3$ sample possessed the lowest quantity of $Y 4$, while $\mathrm{Ph}^{-} 4$ presented the highest internal reference gene transcript. A representative example of $\mathrm{Ph}^{-}$control quantification of $Y 4$ is displayed in Fig. 1C. The results of BCR-ABL1 and Y4 quantification in the control samples are presented in Table V.

For the patients with CML, dPCR amplified the $B C R-A B L 1$ transcript in all exosome samples (median $B C R-A B L 1$ copies/ml of plasma, 11.50 ; range, 4.5-20.25; normalized for plasma volume). The resulting signals were superimposable with those detected in the PB cells of patients with CML, considering both the fluorescence intensity and the absence of background noise (Fig. 1D). The median quantification value of the $Y 4$ transcript was 177.97 copies/ml of plasma (range 35.3-1,419.44; normalized for plasma volume), and the results of $B C R-A B L 1$ and $Y 4$ transcripts quantification in CML patient samples are presented in Table IV.

When comparing the $B C R-A B L 1$ transcript levels detected in the PB cells and tumor-derived exosomes of the patients with CML, no linear association was identified, considering the absolute quantification and the $B C R-A B L 1$ transcript levels normalized for the plasma volume (Figs. 2 and 3, respectively). Nevertheless, excluding case no. 5 (where no $B C R-A B L 1$ transcript copies were identified in PB cells), a trend was identified in the absolute quantification, since patient nos. 4 and 10 exhibited the highest amount of transcript in both PB cells and tumor-derived exosomes, while patient no. 7 possessed the lowest $B C R-A B L 1$ transcript copy number in both $\mathrm{PB}$ cells and tumor-derived exosomes (Fig. 2). This trend was not present when considering the absolute $B C R-A B L 1$ transcript quantification value of PB cells (as determined by dPCR) or 
Table V. Results of the quantification of BCR-ABL1 by dPCR in $\mathrm{Ph}^{-}$controls and heathy controls.

\begin{tabular}{|c|c|c|c|c|c|c|c|c|}
\hline \multirow[b]{2}{*}{ Case no. } & \multicolumn{2}{|c|}{$\begin{array}{c}\text { dPCR PB } \\
\text { cells } B C R-A B L 1\end{array}$} & \multicolumn{3}{|c|}{ dPCR EXO BCR-ABL1 } & \multicolumn{3}{|c|}{ dPCR EXO Y4 } \\
\hline & DOTS & $\begin{array}{l}\text { Copies } / \mu 1 \\
\text { of reaction }\end{array}$ & DOTS & $\begin{array}{l}\text { Copies } / \mu 1 \\
\text { of reaction }\end{array}$ & $\begin{array}{c}\text { Copies } / \mu 1 \\
\text { plasma }\end{array}$ & DOTS & $\begin{array}{l}\text { Copies } / \mu 1 \\
\text { of reaction }\end{array}$ & $\begin{array}{c}\text { Copies/ml } \\
\text { plasma }\end{array}$ \\
\hline $\mathrm{Ph}^{-1} 1$ & 0 & 0 & 0 & 0 & 0 & 5 & 0.398 & 34.11 \\
\hline $\mathrm{Ph}^{-} 2$ & 0 & 0 & 0 & 0 & 0 & 17 & 1.34 & 83.75 \\
\hline $\mathrm{Ph}^{-} 3$ & 0 & 0 & 0 & 0 & 0 & 3 & 0.229 & 14.31 \\
\hline $\mathrm{Ph}^{-} 4$ & 0 & 0 & 2 & 0.164 & 6.58 & 79 & 5.845 & 365.31 \\
\hline Healthy 1 & 0 & 0 & 0 & 0 & 0 & 0 & 0 & 0 \\
\hline Healthy 2 & 0 & 0 & 0 & 0 & 0 & 0 & 0 & 0 \\
\hline Healthy 3 & 0 & 0 & 0 & 0 & 0 & 0 & 0 & 0 \\
\hline Healthy 4 & 0 & 0 & 0 & 0 & 0 & 0 & 0 & 0 \\
\hline Healthy 5 & 0 & 0 & 0 & 0 & 0 & 0 & 0 & 0 \\
\hline Healthy 6 & 0 & 0 & 0 & 0 & 0 & 0 & 0 & 0 \\
\hline Healthy 7 & 0 & 0 & 0 & 0 & 0 & 0 & 0 & 0 \\
\hline Healthy 8 & 0 & 0 & 0 & 0 & 0 & 0 & 0 & 0 \\
\hline Healthy 9 & 0 & 0 & 0 & 0 & 0 & 0 & 0 & 0 \\
\hline Healthy 10 & 0 & 0 & 0 & 0 & 0 & 0 & 0 & 0 \\
\hline
\end{tabular}

The quantification was performed on PB cells and tumor exosomes fraction. In the last columns are reported the results of the quantification of Y4 performed by dPCR on the tumor exosomes fraction APCR, digital PCR; CML, chronic myeloid leukemia; BCR-ABL1, breakpoint cluster region-proto-oncogene 1 tyrosine-protein kinase.

25

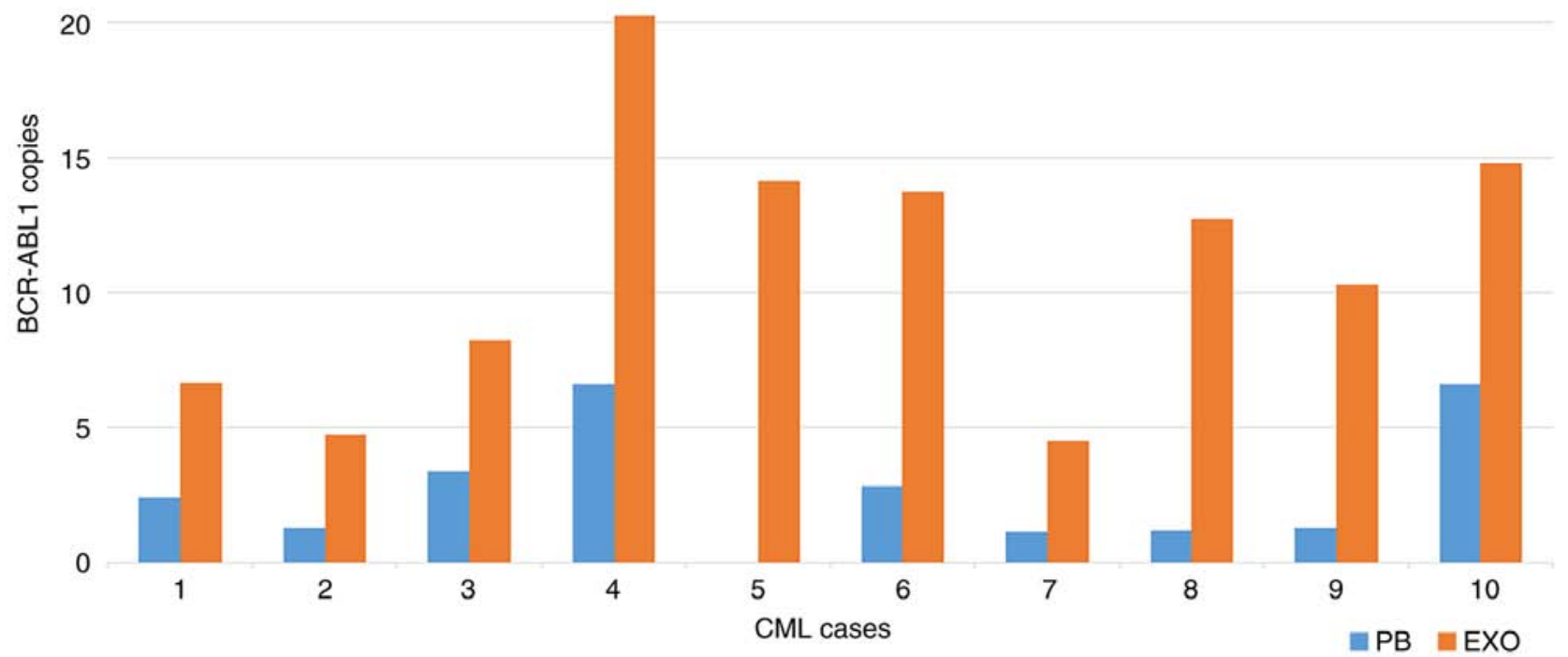

Figure 2. Histogram reporting the BCR-ABL1 transcript quantifications performed on PB cells from the 10 patients with CML (blue bars) and tumor-enriched exosomes (orange bars). The number of BCR-ABL1 transcript in PB cells are reported as copies/reaction, obtained as number of BCR-ABL1 copies/ $\mu 1$ of reaction x $15 \mu \mathrm{l}$ (volume of reaction). The numbers of BCR-ABL1 transcript in tumor-enriched exosomes are reported as copies/ml of plasma, obtained as number of BCR-ABL1 copies/ $\mu 1$ of reaction $\mathrm{x}$ number of plasma used for exosomes isolation. Patient nos. 4 and 10 presented the highest BCR-ABL1 transcript levels, both in PB cells and in tumor-derived exosomes. Patient no. 7 presented the lowest BCR-ABL1 transcript levels, both in PB cells and in tumor-derived exosomes. BCR-ABL1, breakpoint cluster region-proto-oncogene 1 tyrosine-protein kinase; CML, chronic myeloid leukemia; PB, peripheral blood; EXO, exosome.

the ratio $B C R-A B L 1 / Y 4$ transcript on exosomal samples (Fig. 3). Notably, patient no. 4 was the case with the highest level of $B C R-A B L 1$, considering both the absolute and the relative quantification (Figs. 2 and 3). 
Table VI. Results of the dPCR quantification of $Y 4$ performed on tumor exosomes fraction, obtained by SoRTEV ${ }^{\mathrm{TM}}$ EV-RNA Low Volume Enrichment kit, and on total-exosomes fraction obtained by the Total Exosome Isolation kit and Total Exosome RNA and Protein Isolation kit.

\begin{tabular}{|c|c|c|c|c|c|c|}
\hline \multirow[b]{2}{*}{ Case no. } & \multicolumn{3}{|c|}{ dPCR EXO Y4 in tumor-exosomes } & \multicolumn{3}{|c|}{ dPCR EXO Y4 in total exosome fraction } \\
\hline & DOTS & Copies $/ \mu 1$ of reaction & Copies/ml plasma & DOTS & Copies $/ \mu 1$ of reaction & Copies/ml plasma \\
\hline Healthy 6 & 0 & 0 & 0 & 22 & 1.628 & 203.5 \\
\hline Healthy 7 & 0 & 0 & 0 & 18 & 1.258 & 157.25 \\
\hline Healthy 8 & 0 & 0 & 0 & 23 & 1.688 & 211 \\
\hline Healthy 9 & 0 & 0 & 0 & 19 & 1.379 & 172.44 \\
\hline Healthy 10 & 0 & 0 & 0 & 10 & 0.787 & 98.33 \\
\hline CML 1a & 97 & 9.146 & $1,143.25$ & 298 & 21.484 & $2,685.54$ \\
\hline CML 1b & 58 & 4.973 & 621.625 & 164 & 15.757 & $1,969.605$ \\
\hline CML 1c & 18 & 1.288 & 161 & 76 & 7.639 & 954.855 \\
\hline CML 1d & 24 & 1.734 & 108.375 & 54 & 4.35 & 543.85 \\
\hline CML 1e & 11 & 0.909 & 56.813 & 39 & 2.979 & 372.33 \\
\hline CML 5 & 11 & 0.848 & 35.3 & 11 & 0.881 & 110.08 \\
\hline CML 6 & 6 & 0.432 & 54.0 & 14 & 1.107 & 138.42 \\
\hline CML 7 & 30 & 2.39 & 298.75 & 22 & 1.608 & 201.06 \\
\hline CML 8 & 11 & 0.915 & 57.19 & 21 & 1.546 & 193.29 \\
\hline CML 9 & 8 & 0.613 & 38.31 & 20 & 1.432 & 179.01 \\
\hline
\end{tabular}

dPCR, digital PCR; CML, chronic myeloid leukemia; $B C R-A B L 1$, breakpoint cluster region-proto-oncogene 1 tyrosine-protein kinase.

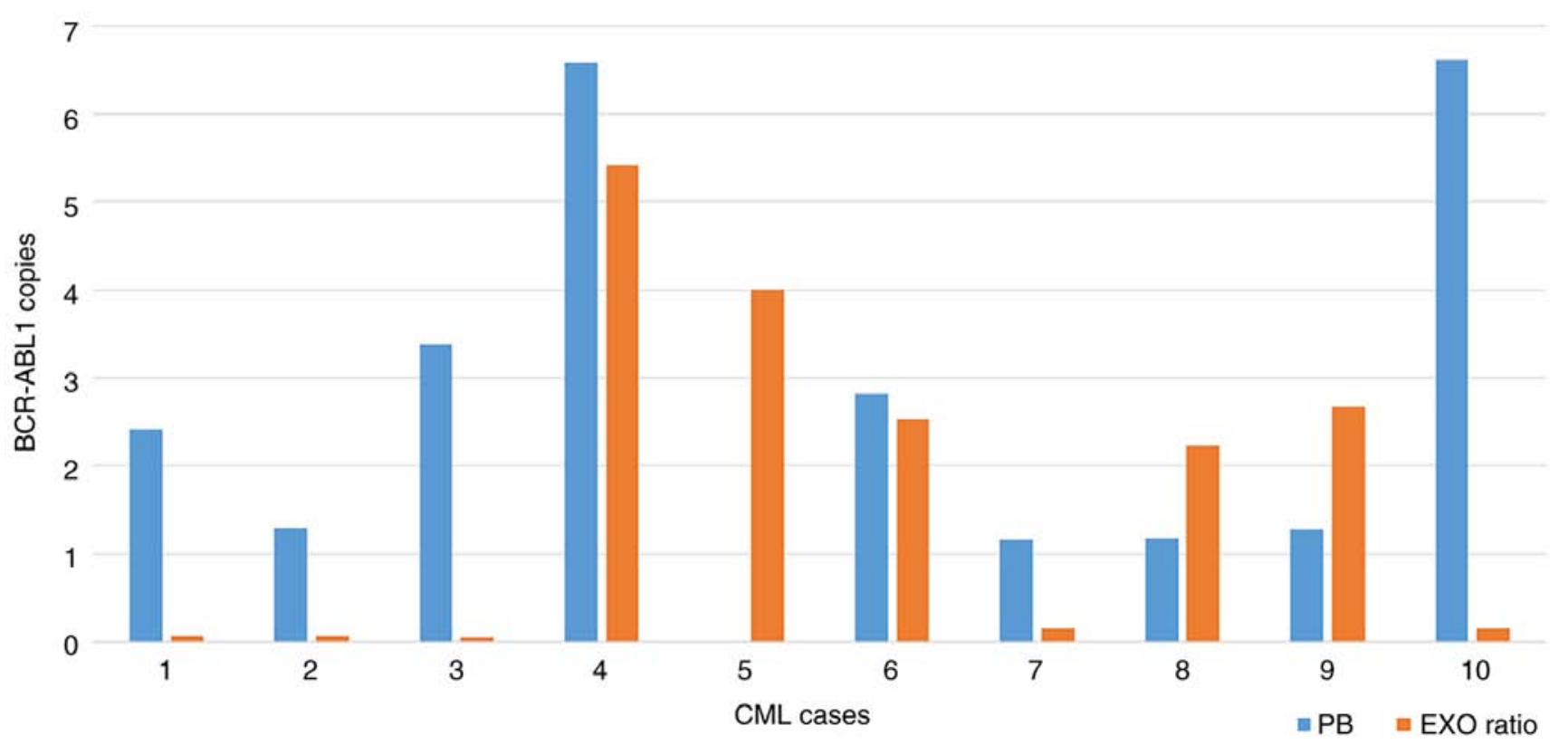

Figure 3. Histogram reporting the BCR-ABL1 transcript quantifications performed on the PB cells from 10 patients with CML (blue bars) and the BCR-ABL1/Y4 tumor-enriched exosomes (orange bars). The number of BCR-ABL1 transcript in PB cells are reported as copies/reaction, obtained as number of BCR-ABL1 copies $/ \mu 1$ of reaction $x 15 \mu 1$ (volume of reaction). The numbers of BCR-ABL1/Y4 transcript in tumor-enriched exosomes are reported as ratio of the BCR-ABL1 copies/ml and the Y4 copies/ml x 10. Patient no. 4 presented the highest BCR-ABL1 transcript levels, both in PB cells and in tumor-derived exosomes. BCR-ABL1, breakpoint cluster region-proto-oncogene 1 tyrosine-protein kinase; CML, chronic myeloid leukemia; PB, peripheral blood; EXO, exosome.

dPCR Y4 quantification in the total-exosome fraction. In order to estimate the total amount of the exosomal RNA, cDNA obtained from exosomes isolated from the plasma of CML and healthy controls, using the Total Exosome Isolation kit and Total Exosome RNA and Protein Isolation kit, were used for $Y 4$ quantification by $\mathrm{dPCR}$. The raw quantification data, expressed as both copies $/ \mathrm{ml}$ of reaction and copies $/ \mathrm{ml}$ of plasma, are reported in Table IV. In the CML samples, the 
median $Y 4$ transcript quantification value in the total-exosome fraction was $286.695 \mathrm{Y} 4$ copies/ml of plasma (range 110.08-2,685.54); while in healthy controls, this was 172.44 Y4 copies/ml of plasma (range 98.33-211) (Table VI).

\section{Discussion}

The present explorative study, which was based on a monocentric cohort of 10 patients in the CP of CML, with DMR under TKI treatment, indicated the potential feasibility of tumor-derived exosome enrichment, in patients with onco-hematological diseases.

The current interest in exosomes is due to their ability to robustly protect and carry information to activate target cells, promoting their epigenetic alteration, transporting membrane receptors, and proteins of interest. In addition to cellular communication, exosomes are known to be associated with immune reactions, cancer viability and invasion, antigen presentation, and cell migration and differentiation (53). Recently, a number of studies have demonstrated the role of these EVs in hematological malignancies (21-23), as well as their involvement at different diseases phases $(33,53)$.

In recent years, various exosome-isolation strategies have been developed. The most promising of these methods for a deep molecular characterization of intra-tumor cell communication encompass the immune-selective enrichments of tumor antigens $(15,18)$. These tools, which act synergistically with innovative molecular biology techniques such as next generation sequencing and dPCR, may improve the accuracy and sensitivity of exosomes analysis $(45,46)$. In this context, the CML model is considered to be particularly suitable, given the presence of BCR-ABL1 as a hallmark indicator of leukemic cells, and the established use of RT-qPCR to monitor MRD. The $B C R-A B L 1$ transcript has previously been detected in the exosomes of patients with CML, but not in those in the CP. Specifically, a previous study demonstrated the possibility of quantifying the $B C R-A B L 1$ transcript in exosomes isolated from the $\mathrm{PB}$ of patients with CML in advanced disease phases, such as accelerating or blast phases. However, they were not be able to detect $B C R-A B L 1$ by nested PCR in CML patients in the CP (44).

To the best of our knowledge, the present study is the first to investigate the possibility of isolating leukemia-derived exosomes from patients with CML, using a commercial kit developed for solid tumors, and based on a proprietary antibody affinity method that selectively enriches tumor-derived exosomes (8). The evaluation of enrichment specificity was determined by $B C R-A B L 1$ transcript detection using dPCR, since it has been demonstrated to be more sensitive and robust than conventional approaches for $B C R-A B L 1$ quantification in CML cases $(45,46)$.

In the healthy controls of the present study, the absence of the $B C R-A B L 1$ and $Y 4$ transcripts confirmed the specificity of the enrichment, although the absence of the fusion gene transcript cannot be considered as absence of exosome isolation. The $B C R-A B L 1$ transcript may not be incorporated in all tumor-derived exosomes, and some EVs may be isolated by non-specific immune-recognition. On the other hand, for a lack of $Y 4$ transcript detection confirmed the power of tumor-derived exosomes enrichment, as $Y 4$ is considered to be a good internal reference gene for exosomes evaluation $(48,54)$, and its absence would indicate a lack of tumor-derived exosomes (as expected in healthy controls). The smear of a FAM signal under the emission threshold was considered as background noise, for both low fluorescence intensity and an abnormal emission pattern (Fig. 1A and 1B). This effect may be due to an auto-fluorescence property of chemical contaminants present in the eluate (such as the resin of the SoRTEV ${ }^{\text {тм }}$ EV-RNA Low Volume Enrichment kit); in the absence of target detection, this may in non-specific reactivity and the production of background noise.

By contrast, in the $\mathrm{Ph}^{-}$control cohort, $\mathrm{Y} 4$ was detectable by $\mathrm{dPCR}$ in all samples. This may reflect the presence of active tumor cells in enrolled patients, and their subsequent release of exosomes. Considering the quantity of $Y 4$ in the $\mathrm{Ph}^{-}$patients, a wide range was appreciated. Even if no correlation analysis between the quantity of $Y 4$ transcript and disease status was attempted, a trend may be observed. Notably, the lowest levels of the internal reference gene (which may reflect the lowest levels of tumor-derived exosomes) were detected in a $\mathrm{Ph}^{-}$patient who had undergone allogenic stem cell transplantation (14.31 Y4 copies/ml plasma), and in a $\mathrm{Ph}^{-}$patient in complete morphological remission (34.11 Y4 copies/ml plasma). Furthermore, the highest detected levels of $Y 4$ transcript (365.21 Y4 copies $/ \mathrm{ml}$ plasma) were observed in a patient with multiple myeloma $\left(\mathrm{Ph}^{-}\right.$ case no. 4) at the point of relapse, when the activity of the leukemia cells was potentially increasing or at its most prominent (Table V). In this case, $2 B C R-A B L 1$ transcript copies were also detected in the cDNA of the tumor-derived exosome. This result may suggest a lack of $B C R-A B L 1$ dPCR quantification specificity, but may also be due to the development of a new $\mathrm{Ph}^{+}$ subclones in a conventionally $\mathrm{Ph}^{-}$disease. This mechanism of subclone (or new leukemia clones) development and selection is possible and has been previously described $(55,56)$. Collectively, these findings highlight the possibility of improving our understanding of tumor heterogeneity by selectively isolating the neoplastic exosomes. Moreover, it is known that the $B C R-A B L 1$ transcript may also be detected in elderly healthy subjects, which may reflect the presence of a group of $\mathrm{Ph}^{+}$cells controlled by the immune system (57).

Finally, in 10 patients in the CP of CML with a DMR under TKI treatment (and in 5 samples of CML patient no. 1 monitored from diagnosis to the achievement of the DMR) the exosome enrichment performed using the SoRTEV ${ }^{\text {Tм }}$ EV-RNA Low Volume Enrichment kit highlighted the presence of the $B C R-A B L 1$ transcript in leukemia-derived EVs. A previous study demonstrated the detectability of this fusion gene transcript in the total exosomes pool of patients affected by CML, not enriched for specific sub-populations; $B C R-A B L 1$ was only detected by conventional nested PCR in patients in the accelerated phase or in blast crisis (44). These results contradict those of the present study, which may be due to the improvements in the specificity of leukemia-derived exosome enrichment methods combined with highly sensitive dPCR quantification.

In order to exclude the possibility that the absence of Y4 RNA reflects an overall lower exosome density in healthy subject plasma, or in patients with prominent DMRs, the total-exosome fraction was isolated from 5 healthy controls and from 10 CML patient samples at different disease phases. A commercial kit was used considering its performance rating 
in published literature (58). Y4 was quantified to evaluate the expression of the reference gene, and to indirectly estimate the exosome concentration in the plasma samples. Samples collected at diagnosis or during the early phase of the therapy response (samples 1a and 1b) possessed a higher amount of $Y 4$ in the total-exosome fraction $(2,685.54$ and 1,969.605 Y4 copies/ml plasma) compared with those of healthy control samples (median, 172.44 Y4 copies/ml plasma; range 98.33-211), or the CML samples with MMR (samples 1c and 1d) or DMR (samples 1e and 5-9; median, 286.695 Y4 copies/ml plasma; range 110.08-954.855). This result confirms that patients with clinical evidence of disease exhibit an increased number of exosomes in the plasma, reflecting the high exosomes-release activity of tumor and leukemic cells (59). Nevertheless, the application of tumor-exosome enrichment in healthy subjects, and in those with CML presenting with MMR or DMR, indicated a notable difference between these two categories. In fact, as a result of tumor-exosomes enrichment, no $Y 4$ signal was detectable in the healthy controls, whilst it was consistent in CML samples derived from patients with both high and low disease levels.

However, the limited residual quantities of some samples do not allow additional experiments, such as the conventional ultracentrifugation. In order to compare the result obtainable using different isolation technologies, included the enrichment approach described in this study, further studies are warranted with this particular aim. Future larger-scale studies will also allow additional analysis, for example the quantification of total exosomes isolated by conventional techniques, which were not possible in this pilot feasibility study. In conclusion, the present study indicated the feasibility of enriching leukemia-derived exosomes by immune-affinity recognition, as reported in solid tumors. Moreover, the detectability of the $B C R-A B L 1$ transcript in the enriched EVs was demonstrated; this indicates novel insight into the detectability of molecular communication between residual leukemic cells resident in the $\mathrm{BM}$, which are considered to be one of the main contributors to the relapse of patients undergoing TKI discontinuation. Considering the biological roles of the exosomes, the presence of the $B C R-A B L 1$ transcript in leukemia-derived exosomes cannot currently be considered to have the same significance as the presence of the fusion gene transcript in PB cells. The implications of $B C R-A B L 1$-positive exosomes on the disease progression status of patients with CP-CML, and their subsequent clinical impact, remain to be fully understood. The present study may be considered the bases for further larger-scale studies, with the aim of investigating these challenges, and broadening the application of tumor-derived exosomes enrichment in the onco-hematology field, where it currently remains to be explored.

\section{Acknowledgements}

Not applicable.

\section{Funding}

This study was supported in part by the European Leukemia Net (ELN)-European Treatment and Outcome Study (EUTOS) and Gimema CML-Working Party, Department of Clinical and Experimental Sciences of University of Brescia funds, and by Cofin 2009.

\section{Availability of data and materials}

All data generated or analyzed during this study are included in this published article or are available from the corresponding author on reasonable request.

\section{Authors' contributions}

DR, SB and CF designed the study; CF, CZ and SB performed the $\mathrm{dPCR}$ analysis; $\mathrm{CF}$ and $\mathrm{CZ}$ performed the exosome enrichment and isolation; MM, MF, NP, FR, FC, AT, EM, LG, TZ and $\mathrm{EAB}$ enrolled the patients and collected the clinical data; SB, CF and DR wrote the manuscript. All authors have read and approved the final manuscript.

\section{Ethics approval and consent to participate}

The present explorative study was approved by the Ethics Committee of Brescia (local study no. NP2370 approved in May, 2016) and performed according to good clinical practice and Declaration of Helsinki. All patients and subjects gave their written informed consent for the enrollment in the study, the use of their samples for research purposes and for the publication of the encompassed data.

\section{Patient consent for publication}

Not applicable.

\section{Competing interests}

The authors declare that they have no competing interests.

\section{References}

1. RahbariM,PecqueuxM,AustD,StephanH,TiebelO,ChatzigeorgiouA, Tonn T, Baenke F, Rao V, Ziegler N, et al: Expression of glypican 3 is an independent prognostic biomarker in primary gastro-esophageal adenocarcinoma and corresponding serum exosomes. J Clin Med 8: E696, 2019.

2. Wang YL, Liu LC, Hung Y, Chen CJ, Lin YZ, Wu WR and Wang SC: Long non-coding RNA HOTAIR in circulatory exosomes is correlated with ErbB2/HER2 positivity in breast cancer. Breast 46: 64-69, 2019.

3. Zhao A, Guo L, Xu J, Zheng L, Guo Z, Ling Z, Wang Land Mao W: Identification and validation of circulating exosomes-based liquid biopsy for esophageal cancer. Cancer Med 8: 3566-3574, 2019.

4. Han S, Huo Z, Nguyen K, Zhu F, Underwood PW, Basso KBG, George TJ and Hughes SJ: The proteome of pancreatic cancer-derived exosomes reveals signatures rich in key signaling pathways. Proteomics 19: e1800394, 2019.

5. Grange C, Brossa A, Bussolati B, Grange C, Brossa A and Bussolati B: Extracellular vesicles and carried miRNAs in the progression of renal cell carcinoma. Int J Mol Sci 20: E1832, 2019.

6. Wong $\mathrm{CH}$ and Chen YC: Clinical significance of exosomes as potential biomarkers in cancer. World JClin Cases 7: 171-190, 2019.

7. Kinjyo I, Bragin D, Grattan R, Winter SS and Wilson BS: Leukemia-derived exosomes and cytokines pave the way for entry into the brain. J Leukoc Biol 105: 741-753, 2019.

8. Zarovni N, Corrado A, Guazzi P, Zocco D, Lari E, Radano G, Muhhina J, Fondelli C, Gavrilova J and Chiesi A: Integrated isolation and quantitative analysis of exosome shuttled proteins and nucleic acids using immunocapture approaches. Methods 87: 46-58, 2015. 
9. Mathivanan S, Ji H and Simpson RJ: Exosomes: Extracellular organelles important in intercellular communication. J Proteomics 73: 1907-1920, 2010.

10. Lakkaraju A and Rodriguez-Boulan E: Itinerant exosomes: Emerging roles in cell and tissue polarity. Trends Cell Biol 18 199-209, 2008.

11. van Niel G,Porto-Carreiro I, Simoes S and Raposo G: Exosomes: A common pathway for a specialized function. J Biochem 140: $13-21,2006$

12. Février B and Raposo G: Exosomes: Endosomal-derived vesicles shipping extracellular messages. Curr Opin Cell Biol 16: 415-421, 2004.

13. Miller IV and Grunewald TG: Tumour-derived exosomes: Tiny envelopes for big stories. Biol Cell 107: 287-305, 2015.

14. Simpson RJ, Jensen SS and Lim JW: Proteomic profiling of exosomes: Current perspectives. Proteomics 8: 4083-4099, 2008.

15. Zocco D, Ferruzzi P, Cappello F, Kuo WP and Fais S: Extracellular vesicles as shuttles of tumor biomarkers and anti-tumor drugs. Front Oncol 4: 267, 2014

16. The fifth international meeting of ISEV, ISEV2016, Rotterdam, the Netherlands, 4-7 May, 2016, OPW 3.8. J Extracell Vesicles 5: 31552,2016

17. Jiang S, Hu C, Liu P and Lu M: Tumor-derived exosomes in cancer metastasis risk diagnosis and metastasis therapy. Clin Transl Oncol 21: 152-159, 2019.

18. Wen SW, Lima LG, Lobb RJ, Norris EL, Hastie ML, Krumeich S and Möller A: Breast cancer-derived exosomes reflect the cell-of-origin phenotype. Proteomics 19: e1800180, 2019.

19. Tatischeff I: Prostate cancer under the light of tumor cells-derived extracellular vesicles. Cancer Res Front 3: 83-111, 2017

20. Théry C and Witwer K: ISEV2018 abstract book. J Extracell Vesicles 7 (Suppl 1): 1461450, 2018.

21. Jafarzadeh N, Safari Z, Pornour M, Amirizadeh N Forouzandeh Moghadam M and Sadeghizadeh M: Alteration of cellular and immune-related properties of bone marrow mesenchymal stem cells and macrophages by K562 chronic myeloid leukemia cell derived exosomes. J Cell Physiol 234: 3697-3710, 2019.

22. Wierz M, Pierson S, Gargiulo E, Guerin C, Moussay E and Paggetti J: Purification of leukemia-derived exosomes to study microenvironment modulation. Methods Mol Biol 1884: 231-245, 2019.

23. Cheng H, Sun G and Cheng T: Hematopoiesis and microenvironment in hematological malignancies. Cell Regen (Lond) 7: 22-26, 2018.

24. Bouyssou JM, Liu CJ, Bustoros M, Sklavenitis-Pistofidis R, Aljawai Y, Manier S, Yosef A, Sacco A, Kokubun K, Tsukamoto S, et al: Profiling of circulating exosomal miRNAs in patients with waldenström macroglobulinemia. PLoS One 13: e0204589, 2018

25. Tadokoro H, Umezu T, Ohyashiki K, Hirano T and Ohyashiki JH: Exosomes derived from hypoxic leukemia cells enhance tube formation in endothelial cells. J Biol Chem 288: 34343-34351, 2013.

26. Sharifi H, Shafiee A, Molavi G, Razi E, Mousavi N, Sarvizadeh M and Taghizadeh M: Leukemia-derived exosomes: Bringing oncogenic signals to blood cells. J Cell Biochem 120: 16307-16315, 2019.

27. Yao Y, Wang C, Wei W, Shen C, Deng X, Chen L, Ma L and Hao S: Dendritic cells pulsed with leukemia cell-derived exosomes more efficiently induce antileukemic immunities. PLoS One 9: e91463, 2014

28. Szczepanski MJ, Szajnik M, Welsh A, Whiteside TL and Boyiadzis M: Blast-derived microvesicles in sera from patients with acute myeloid leukemia suppress natural killer cell function via membrane-associated transforming growth factor-beta1. Haematologica 96: 1302-1309, 2011

29. Wojtuszkiewicz A, Schuurhuis GJ, Kessler FL, Piersma SR, Knol JC, Pham TV, Jansen G, Musters RJ, van Meerloo J, Assaraf YG, et al: Exosomes secreted by apoptosis-resistant acute myeloid leukemia (AML) blasts harbor regulatory network proteins potentially involved in antagonism of apoptosis. Mol Cell Proteomics 15: 1281-1298, 2016.

30. Huan J, Hornick NI, Goloviznina NA, Kamimae-Lanning AN, David LL, Wilmarth PA, Mori T, Chevillet JR, Narla A, Roberts CT Jr, et al: Coordinate regulation of residual bone marrow function by paracrine trafficking of AML exosomes. Leukemia 29: 2285-2295, 2015.

31. Wang J, De Veirman K, Faict S, Frassanito MA, Ribatti D, Vacca A and Menu E: Multiple myeloma exosomes establish a favourable bone marrow microenvironment with enhanced angiogenesis and immunosuppression. J Pathol 239: 162-173, 2016.
32. Yeh YY, Ozer HG, Lehman AM, Maddocks K, Yu L, Johnson AJ and Byrd JC: Characterization of CLL exosomes reveals a distinct microRNA signature and enhanced secretion by activation of BCR signaling. Blood 125: 3297-3305, 2015.

33. Corrado C, Saieva L, Raimondo S, Santoro A, De Leo G and Alessandro R: Chronic myelogenous leukaemia exosomes modulate bone marrow microenvironment through activation of epidermal growth factor receptor. J Cell Mol Med 20: 1829-1839, 2016.

34. Rowley JD: Letter: A new consistent chromosomal abnormality in chronic myelogenous leukaemia identified by quinacrine fluorescence and Giemsa staining. Nature 243: 290-293, 1973.

35. Druker BJ, Sawyers CL, Kantarjian H, Resta DJ, Reese SF, Ford JM, Capdeville R and Talpaz M: Activity of a specific inhibitor of the BCR-ABL tyrosine kinase in the blast crisis of chronic myeloid leukemia and acute lymphoblastic leukemia with the philadelphia chromosome. N Engl J Med 344: 1038-1042, 2001.

36. Sonoyama J, Matsumura I, Ezoe S, Satoh Y, Zhang X, Kataoka Y, Takai E, Mizuki M, Machii T, Wakao H and Kanakura Y: Functional cooperation among Ras, STAT5, and phosphatidylinositol 3-kinase is required for full oncogenic activities of BCR/ABL in K562 cells. J Biol Chem 277: 8076-8082, 2002.

37. Cross NC, White HE, Colomer D, Ehrencrona H, Foroni L, Gottardi E, Lange T, Lion T, Machova Polakova $\mathrm{K}$, Dulucq S, et al: Laboratory recommendations for scoring deep molecular responses following treatment for chronic myeloid leukemia. Leukemia 29: 999-1003, 2015.

38. Egan D and Radich J: Monitoring disease burden in chronic myeloid leukemia: Past, present, and future. Am J Hematol 91: 742-746, 2016.

39. Mahon FX, Réa D, Guilhot J, Guilhot F, Huguet F, Nicolini F, Legros L, Charbonnier A, Guerci A, Varet B, et al: Discontinuation of imatinib in patients with chronic myeloid leukaemia who have maintained complete molecular remission for at least 2 years: The prospective, multicentre stop imatinib (STIM) trial. Lancet Oncol 11: 1029-1035, 2010.

40. Russo D, Malagola M, Skert C, Cancelli V, Turri D, Pregno P, Bergamaschi M, Fogli M, Testoni N, De Vivo A, et al: Managing chronic myeloid leukaemia in the elderly with intermittent imatinib treatment. Blood Cancer J 5: e347, 2015.

41. Ross DM, Masszi T, Gómez Casares MT, Hellmann A, Stentoft J, Conneally E, Garcia-Gutierrez V, Gattermann N, le Coutre PD, Martino B, et al: Durable treatment-free remission in patients with chronic myeloid leukemia in chronic phase following frontline nilotinib: 96-week update of the ENESTfreedom study. J Cancer Res Clin Oncol 144: 945-954, 2018.

42. Cortes J, Rea D and Lipton JH: Treatment-free remission with first- and second-generation tyrosine kinase inhibitors. Am J Hematol 94: 346-357, 2019.

43. Bocchia M, Sicuranza A, Abruzzese E, Iurlo A, Sirianni S, Gozzini A, Galimberti S, Aprile L, Martino B, Pregno P, et al: Residual peripheral blood CD26 ${ }^{+}$leukemic stem cells in chronic myeloid leukemia patients during TKI therapy and during treatment-free remission. Front Oncol 8: 194, 2018

44. Kang KW, Jung JH, Hur W, Park J, Shin H, Choi B, Jeong H, Kim DS, Yu ES, Lee SR, et al: The potential of exosomes derived from chronic myelogenous leukaemia cells as a biomarker. Anticancer Res 38: 3935-3942, 2018.

45. Bernardi S, Ruggieri G, Malagola M, Cancelli V, Cattina F, Polverelli N,Zanaglio C, Perucca S, Re F, Montanelli A and Russo D: Digital PCR (Dpcr) a step forward to detection and quantification of minimal residual disease (MRD) in Ph+/BCR-ABL1 chronic myeloid leukemia (CML). J Mol Biomark Diagn 8: 330, 2017.

46. Bernardi S, Malagola M, Zanaglio C, Polverelli N, Dereli Eke E, D'Adda M, Farina M, Bucelli C, Scaffidi L, Toffoletti E, et al: Digital PCR improves the quantitation of DMR and the selection of CML candidates to TKIs discontinuation. Cancer Med 8: 2041-2055, 2019

47. Tosar JP, Gámbaro F, Sanguinetti J, Bonilla B, Witwer KW and Cayota A: Assessment of small RNA sorting into different extracellular fractions revealed by high-throughput sequencing of breast cell lines. Nucleic Acids Res 43: 5601-5616, 2015.

48. Yeri A, Courtright A, Reiman R, Carlson E, Beecroft T, Janss A, Siniard A, Richholt R, Balak C, Rozowsky J, et al: Total extracellular small RNA profiles from plasma, saliva, and urine of healthy subjects. Sci Rep 7: 44061, 2017.

49. Li C, Qin F, Hu F, Xu H, Sun G, Han G, Wang T and Guo M: Characterization and selective incorporation of small non-coding RNAs in non-small cell lung cancer extracellular vesicles. Cell Biosci 8: 2, 2018 
50. Skog J, Würdinger T, van Rijn S, Meijer DH, Gainche L, Sena-Esteves M, Curry WT Jr, Carter BS, Krichevsky AM and Breakefield XO: Glioblastoma microvesicles transport RNA and proteins that promote tumour growth and provide diagnostic biomarkers. Nat Cell Biol 10: 1470-1476, 2008.

51. Slonchak A, Clarke B, Mackenzie J, Amarilla AA, Setoh YX and Khromykh AA: West Nile virus infection and interferon alpha treatment alter the spectrum and the levels of coding and noncoding host RNAs secreted in extracellular vesicles. BMC Genomics 20: 474, 2019.

52. Bardi GT, Al-Rayan N, Richie JL, Yaddanapudi K and Hood JL: Detection of inflammation-related melanoma small extracellular vesicle (sEV) mRNA content using primary melanocyte sEVs as a reference. Int J Mol Sci 20: E1235, 2019.

53. Chen T, Zhang G, Kong L, Xu S, Wang Y and Dong M: Leukemia-derived exosomes induced IL-8 production in bone marrow stromal cells to protect the leukemia cells against chemotherapy. Life Sci 221: 187-195, 2019.

54. Anfossi S, Babayan A, Pantel K and Calin GA: Clinical utility of circulating non-coding RNAs-an update. Nat Rev Clin Oncol 15: 541-563, 2018

55. Park SJ, Lee HW, Jeong SH, Park JS, Kim HC, Seok JY, Kim HJ and Cho SR: Acquisition of a BCR-ABL1 transcript in a patient with disease progression from MDS with fibrosis to AML with myelodysplasia-related changes. Ann Clin Lab Sci 41: 379-384, 2011.
56. Miki K, Obara N,Makishima K, SakamotoT,Kusakabe M,Kato T, Kurita N, Nishikii H, Yokoyama Y, Sakata-Yanagimoto M, et al: An unprecedented case of p190 BCR-ABL chronic myeloid leukemia diagnosed during treatment for multiple myeloma: A case report and review of the literature. Case Rep Hematol 2018: 7863943, 2018

57. Boquett JA, Alves JR and de Oliveira CE: Analysis of BCR/ABL transcripts in healthy individuals. Genet Mol Res 12: 4967-4971, 2013.

58. Serrano-Pertierra E, Oliveira-Rodríguez M, Rivas M, Oliva P, Villafani J, Navarro A, Blanco-López MC and CernudaMorollón E: Characterization of plasma-derived extracellular vesicles isolated by different methods: A comparison study. Bioengineering (Basel) 6: E8, 2019.

59. Navarro-Tableros V, Gomez Y, Camussi G and Brizzi MF: Extracellular vesicles: New players in ymphomas. Int J Mol Sci 20: E41,2018.

This work is licensed under a Creative Commons Attribution-NonCommercial-NoDerivatives 4.0 International (CC BY-NC-ND 4.0) License. 